\title{
A Combination of Waste Biomass Activated Carbon and Nylon Nanofiber for Removal of Triclosan from Aqueous Solutions
}

\author{
Nor Khoriha Eliysa Mohd Khori ${ }^{1}$, Salmiati ${ }^{1,2 *}$, Tony Hadibarata ${ }^{3}$, Zulkifli Yusop ${ }^{1,2}$ \\ ${ }^{1}$ Department of Water and Environmental Engineering, School of Civil Engineering, Faculty of Engineering, Universiti Teknologi Malaysia, 81310 Skudai, \\ Johor, Malaysia. \\ ${ }^{2}$ Centre for Environmental Sustainability and Water Security (IPASA), Research Institute for Sustainable Environment (RISE), Universiti Teknologi \\ Malaysia, 81310 Skudai, Johor, Malaysia. \\ ${ }^{3}$ Department of Environmental Engineering, Faculty of Engineering and Science, Curtin University, Malaysia, CDT 250, 98009 Miri Sarawak, Malaysia
}

Received: 25/03/2020

Accepted: 26/06/2020

Published: 20/09/2020

\begin{abstract}
Triclosan (TCS) is one of the biocide used as antibacterial and antifungal agent to kill and hinder the growth of bacteria and also it is used in many personal care and health care products. However, TCS can cause health and environmental problems such as environmental pollutions, acute toxicity, etc. The aim of this study is to investigate the removal of TCS from aqueous solution by combining the coconut pulp waste (Cocos nuciefera) activated carbon (AC) with nylon 6,6 membrane. To this end, first, the effects of physico-chemical characteristics of the membrane were studied. The nylon 6,6 membrane (14 wt.\%] was prepared using electrospinning machine with injection rate at $0.4 \mathrm{~mL} / \mathrm{h}$, tip-to-collector distance at $15 \mathrm{~cm}$, rotation speed at $1000 \mathrm{rpm}$, and applied voltage at $26 \mathrm{kV}$. The parameters studied for the membrane during the adsorption test were contact time, adsorbent dosage, agitation speed, initial TCS concentration, $\mathrm{pH}$, and temperature of the TCS solution. The filtration test was done using flat sheet membrane test machine at pressure 1.0 bar. The characteristics of the membrane were analysed using the FESEM and FTIR tests. Based on the obtained results, the nylon 6,6 membrane can remove $90.2 \%$ of TCS within 5 minutes; the removal rate increased to $100 \%$ in less than 5 minutes after the membrane was combined with AC. This study proved that the combination of $\mathrm{AC}$ and nylon 6,6 membrane is able to maximize the TCS removal from water.
\end{abstract}

Keywords: Triclosan; Activated carbon; Coconut pulp waste; Nylon 6,6 membrane

\section{Introduction}

Triclosan (TCS) (5-chloro-2-(2,4-dichlorophenoxy) phenol) is a chlorinated aromatic compound with the molecular formula $\mathrm{C}_{12} \mathrm{H}_{7} \mathrm{Cl}_{3} \mathrm{O}_{2}$ and molecular weight of $289.54 \mathrm{~g} / \mathrm{mol}$. This organic compound, in the form of white powders, has functional groups of both ethers and phenols. Triclosan is one of the antibacterial and antifungal agents that are normally used in medical and consumer products, such as surgical scrubs, toothpastes, hand wash soaps, mouthwash, shampoos, plastics, toys, textiles, and deodorants [1]. It has the ability to hinder the growth of microorganisms, and due to its presence in many consumer products, it has been detected in most of the sediments, biosolids, surface water, soil, and aquatic species [2].

Though TCS is an antibacterial agent, it also poses a potential risk to the human health and the environment. Zhu et al. [3] reported that TCS was detected in $97 \%$ of urine samples of 471 men with concentrations from 0.41 to $2.95 \mathrm{ng}$ (mg creatinine) $)^{-1}$ and it caused some adverse effects to the semen quality such as low sperm production and poor forward mobility. Moreover, TCS has a high bioaccumulation potential and it can enter the food web system [4]. TCS can also cause toxicity to some aquatic life species such as algae, planktons, fishes, and frogs [5-10].

Therefore, several treatment methods have been implemented to remove TCS from the water, including those using cellulose acetate (CA) membrane [11], ammonia amendment and bioaugmentation in nitrifying activated sludge [12], dielectric barrier discharge plasma combined with activated carbon fibers [13], structure-directing agent modified mesoporous MIL-53 (Al) [14], dissolved organic matter on soybean peroxidase-mediated [15], ozonation [16], and microalgal species [17]. However, these treatments involved complex procedures, high costs of treatments and maintenance, large volumes of chemicals, and long

Corresponding author: Salmiati, (a) Department of Water and Environmental Engineering, School of Civil Engineering, Faculty of Engineering, Universiti Teknologi Malaysia, 81310 Skudai, Johor, Malaysia. (b) Centre for Environmental Sustainability and Water Security (IPASA), Research Institute for Sustainable Environment (RISE), Universiti Teknologi Malaysia, 81310 Skudai, Johor, Malaysia. ${ }^{3}$ Department of Environmental Engineering, Faculty of Engineering and Science, Curtin University, Malaysia, CDT 250, 98009 Miri Sarawak, Malaysia. Email: salmiati@utm.my. 
processing times [18].

In recent years, the adsorption process has been one of the popular methods applied to remove chemicals and dyes in water and wastewater treatments due to its advantages of having less processing procedures with less sludge being produced. Several adsorption studies to remove TCS were done using rice strawderived activated carbon [19], charcoal-based activated carbon [20], conventional activated carbon [21], civilian protective gas mask activated carbon [22], magnetic carbon composites from hydrochar [23], and wastewater biosolids-derived biochar [24]. High surface areas, micro-porous structures, and high degrees of surface reactivity cause activated carbons to become versatile adsorbents, particularly effective for the adsorption of organic and inorganic pollutants from aqueous solutions [25].

However, the preparation of commercial activated carbons is a costly activity, which has encouraged researchers to search for low-cost materials as alternatives [26]. There are many types of natural wastes used as low-cost adsorbents such as human hair, sheep wool, cane bagasse, and many more [27, 28]. Among all, agricultural wastes are one of the promising sources as they are inexpensive, easy to collect, and environmentally friendly [29]. Furthermore, they have a high efficiency in trapping and removing chemicals and dyes from water due to possessing many functional groups such as alcohols, phenolic, amido, amino, carboxyl, carbonyl, and ester [30]. The agricultural wastes from coconut trees have become one of the promising materials to be used as adsorbents due to their abundance in nature, cheaper price, high porous structures, and high absorption capability. The coconut tree parts commonly used as adsorbents are the bunch [29], frond [31], pulp waste [32], husk [33], coir [34], leaves [35], and shell [36].

In addition, membrane is one of the technologies used for removal of various chemicals and pollutants from water. This advanced, well-known treatment technology has become one of the most preferred options for water and wastewater treatments in food industries, chemical industries, and pharmaceutical industries [37-39]. Such popularity of membrane treatment is because of many advantages such as no addition of chemicals required, no secondary pollutants produced, low energy consumption, easy to handle, low operating and maintenance costs, easy to scale-up, high porous structure, and high recovery and reusability [40, 41]. Most of the membranes are made from polymeric materials. Nylon 6,6 is one of the polyamide group that is excellent in mechanical strength, toughness, rigidity, and stability with self-lubricating properties and cost effectiveness in nature [42, 43]. It is also hydrophilic, thin enough, highly porous, highly permeant, acceptable in fouling resistant, and low complicated in structures [44]. These advantages have promoted nylon as a functional polymer for many biomedical and environmental applications [43].

However, finding the best and the most affordable treatments for TCS (because of its long-term negative effects on the aquatic life, wild life, and human health) has remained a concern for researchers working in this field. Therefore, the aim of this research is to study the efficiency of combining both adsorption and filtration methods to remove TCS from water. The objectives of this study are to investigate the physico-chemical characteristics of nylon 6,6 membrane and to examine their effect on the TCS removal from water.

\section{Materials and Methods \\ 2.1 Chemical}

In this study, the following chemicals were used: TCS and acetic acid that were supplied by Merck KGaA (Darmstadt, Germany), Tween 80 supplied by Sigma-Aldrich, ethanol $96 \%$ obtained from Qrec $^{\mathrm{TM}}$ (Malaysia), Nylon 6,6 (polyamide 6,6) pellets supplied by DSM Co. (Netherlands), and formic acid supplied by HmbG Chemicals (Barcelona, Spain). The coconut pulp waste activated carbon was prepared during the preliminary study [45]. The physical and chemical characteristics of TCS and nylon 6,6 are shown in Table 1 .

Table 1: Physico-chemical characteristics of TCS and nylon 6,6

\begin{tabular}{|c|c|c|}
\hline & TCS & Nylon 6,6 \\
\hline $\begin{array}{l}\text { Chemical } \\
\text { structure }\end{array}$ & & 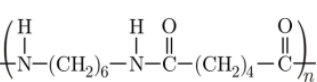 \\
\hline IUPAC name & $\mid \begin{array}{c}\text { 5-chloro-2-(2,4- } \\
\text { dichlorophenoxy)phenol }\end{array}$ & $\begin{array}{c}\text { Poly[imino(1,6- } \\
\text { dioxohexamethylene) } \\
\text { iminohexamethylene] }\end{array}$ \\
\hline Appearance & White solid & White pellets \\
\hline Physical state & Solid & Solid \\
\hline Molecular weight & $289.54 \mathrm{~g} \cdot \mathrm{mol}^{-1}$ & $262.3458 \mathrm{~g} \mathrm{~mol}^{-1}$ \\
\hline $\begin{array}{c}\text { Chemical } \\
\text { formula }\end{array}$ & $\mathrm{C}_{12} \mathrm{H}_{7} \mathrm{C}_{13} \mathrm{O}_{2}$ & $\mathrm{C}_{12} \mathrm{H}_{22} \mathrm{~N}_{2} \mathrm{O}_{2}$ \\
\hline Solubility & $\begin{array}{c}\text { ethanol, methanol, } \\
\text { diethyl ether, strongly } \\
\text { basic solutions, and } \\
\text { slightly soluble in water } \\
\left(10 \mathrm{mg} / \mathrm{L} \text { at } 20^{\circ} \mathrm{C}\right) \\
\end{array}$ & $\begin{array}{l}\text { Soluble in acid, slightly } \\
\text { soluble in boiling water }\end{array}$ \\
\hline Melting point & $55-57^{\circ} \mathrm{C}$ & $255-265^{\circ} \mathrm{C}$ \\
\hline
\end{tabular}

A $500 \mathrm{mg} / \mathrm{L}$ of TCS stock solution was prepared in $500 \mathrm{~mL}$ volumetric flask by dissolving $250 \mathrm{mg}$ TCS powder into $500 \mathrm{~mL}$ ethanol with $0.1 \%$ Tween 80 . Tween 80 is a surfactant that can solubilize hydrophobic organic compound and increase the treatment process efficiency to remove hydrophobic particles in water and soil. As stated by Cheng et al. [46], Tween 80 has many advantages such as cheap, low toxicity to environment, low polarity, and also has high solubilization capacity. As followed by Behera et al. [20], the stock solution was stored in refrigerator at temperature $\pm 4{ }^{\circ} \mathrm{C}$ and was used within one month from its preparation date. The standard solutions for adsorption process were prepared by diluting stock solution with distilled water.

\subsection{Preparation of the nylon 6,6 membrane}

Nylon 6,6 membrane was fabricated in an electrospinning machine (FNM Ltd., Iran). The preparation of one membrane sheet was done within three days. Firstly, $5 \mathrm{ml}$ of acetic acid and $5 \mathrm{ml}$ of formic acid were poured in a $30 \mathrm{ml}$ glass bottle. Then, $1.40 \mathrm{~g}$ of Nylon 6,6 pellets were weighed using analytical weighing scale. The Nylon 6,6 pellets were dissolved with acetic acid-formic acid solution using magnetic stirrer for 12 hours. This procedure was done in order to get a homogenous solution.

For the electrospinning process, several parameters were set up for fabrication of Nylon 6,6 membrane. $5 \mathrm{ml}$ syringe and 0.6 x 32 $\mathrm{mm}$ needles supplied by Terumo ${ }^{\circledR}$ (Canada) were used in this process. Firstly, the collector drum was covered with aluminum net as a membrane base support. This step was carried out so that the membrane sheet can be removed easily. The Nylon 6,6 solution prepared was sucked into the syringe and placed at the 
syringe pump holder. A high voltage was supplied by clipping a small crocodile clipper at the middle of the needle used. As performed by Jasni et al. [43], the jetting flow rate, supplied voltage, drum collector speed, and tip-to-collector distance were set to $0.4 \mathrm{~mL} / \mathrm{h}, 26 \mathrm{kV}, 1000 \mathrm{rpm}$, and $15 \mathrm{~cm}$, respectively. Then, the membrane sheet produced was removed from the drum collector and was dried in a clean cupboard at room temperature for 24 hours. Then, it was stored in a clean container for further research.

\subsection{Adsorption studies}

The adsorption studies of TCS adsorption using Nylon 6,6 membrane were conducted by means of $100 \mathrm{~mL}$ conical flask. Based on Jasni et al. [43], the batch studies were conducted in order to analyse the effect of various parameters on the uptake of TCS onto Nylon 6,6 membrane. As suggested by Muhamad et al. [47], for adsorption performance experiment, the membrane sheet was cut to smaller pieces ( $5 \mathrm{~mm} \times 5 \mathrm{~mm}$ ) before being weighed using analytical weighing scale. The adsorption tests were conducted using a conical flask and a shaker [43, 48]. The effects parameters analysed in this experiment were contact time, adsorbent dosage, agitation speed, initial TCS concentration, initial $\mathrm{pH}$ of TCS solution, and temperature.

The effects of contact time were studied from 10 minutes until 6 hours. Next, the effects of membrane dosage were investigated using $0.01 \mathrm{~g}, 0.05 \mathrm{~g}, 0.10 \mathrm{~g}, 0.15 \mathrm{~g}$, and $0.20 \mathrm{~g}$ of nylon 6,6 membrane. For agitation speed, the speeds of orbital shaker were tested from $50 \mathrm{rpm}$ to $250 \mathrm{rpm}$ with $50 \mathrm{rpm}$ interval. Then, the effects of TCS initial concentration were analysed at $5 \mathrm{mg} / \mathrm{L}, 10$ $\mathrm{mg} / \mathrm{L}, 30 \mathrm{mg} / \mathrm{L}, 50 \mathrm{mg} / \mathrm{L}, 70 \mathrm{mg} / \mathrm{L}$, and $90 \mathrm{mg} / \mathrm{L}$, and the effect of $\mathrm{pH}$ was investigated by varying the value from 3.0 to 9.0 . Lastly, the effect of temperature was studied using incubator shaker at temperature $25{ }^{\circ} \mathrm{C}$ to $60{ }^{\circ} \mathrm{C}$. A summary of design parameters for TCS adsorption using nylon 6,6 membrane is tabulated in Table 2. The remaining of the TCS concentration in water after adsorption treatment was determined using Ultraviolet-Visible (UV-Vis) Spectrophotometer (NANOCOLOR® UV/Vis Macherey-Nagel) at maximum wavelength of $279 \mathrm{~nm}$.

Table 2: The design parameters for TCS adsorption using nylon 6,6 membrane

\begin{tabular}{|l|c|c|c|c|c|c|}
\hline Parameters & $\begin{array}{c}\text { Contact } \\
\text { time }(\mathbf{h r})\end{array}$ & $\begin{array}{c}\text { Membrane } \\
\text { mass }(\mathbf{g})\end{array}$ & $\begin{array}{c}\text { speed } \\
(\mathbf{r p m})\end{array}$ & $\begin{array}{c}\text { TCS conc. } \\
(\mathbf{m g} / \mathbf{L})\end{array}$ & $\mathbf{p H}$ & $\begin{array}{c}\text { Temperature } \\
\left({ }^{\circ} \mathbf{C}\right)\end{array}$ \\
\hline Contact time & $\mathbf{0 . 1 7 - 6 . 0 0}$ & 0.01 & 150 & 5.0 & 5.6 & 25 \\
\hline $\begin{array}{l}\text { Adsorbent } \\
\text { dosage }\end{array}$ & 4.00 & $\mathbf{0 . 0 1 - 0 . 1 5}$ & 150 & 5.0 & 5.6 & 25 \\
\hline Agitation & 4.00 & 0.01 & $\mathbf{5 0 - 2 5 0}$ & 5.0 & 5.6 & 25 \\
\hline TCS conc. & 4.00 & 0.01 & 150 & $\mathbf{5 . 0 - 9 0 . 0}$ & 5.6 & 25 \\
\hline pH & 4.00 & 0.01 & 150 & 5.0 & $\mathbf{3 . 0 - 9 . 0}$ & 25 \\
\hline Temperature & 4.00 & 0.01 & 150 & 5.0 & 5.6 & $\mathbf{2 5 - 6 0}$ \\
\hline
\end{tabular}

\subsection{Filtration}

Filtration experiments were done using the flat sheet membrane test. The filtration test was done to analyse the water flux, TCS flux, and permeate concentration of TCS solution after filtering with nylon 6,6 membrane. The membrane sheet was cut to an oval shape with $57 \mathrm{~mm}$ diameter to fit in the permeation cell. Then, the cell was tightened with screws. Afterward, the distilled water was poured in the feed tank for further tests. Next, after setting the permeation cell and tightening all screws, the membrane compaction test was conducted to allow all the membrane pores to be filled and be in contact with water. The compaction test was done using $4000 \mathrm{~mL}$ distilled water with 1.5 bar pressure for one hour or until a stable permeation rate was achieved. The volume of permeate water from the membrane test cell outlet was recorded every 5 minutes to check the permeation rate pattern. After the permeation volume became stable, the pressure was reduced to 1.0 bar.

Then, the water flux test proceeded using distilled water. The volume of permeate water were recorded every 5 minutes. After that, the distilled water was removed and replaced with $4000 \mathrm{~mL}$ of $5 \mathrm{mg} / \mathrm{L}$ TCS solution for filtration process and TCS flux analysis. For TCS flux experiment, the volume of TCS solution permeated from the permeation cell was recorded every 5 minutes. Besides that, the TCS samples were taken from permeation cell and feed tank for TCS removal analysis. The entire membrane filtration tests were done at room temperature. The flux value was calculated using Equation (1) as follows:

Flux, $J\left(\mathrm{~L} / \mathrm{m}^{2} \mathrm{~h}\right)=(V / t) / A$

where $V / t(\mathrm{~L} / \mathrm{h})$ is volume permeation rate and $A\left(\mathrm{~m}^{2}\right)$ is membrane area $\left(A=0.002124 \mathrm{~m}^{2}\right)$.

\subsection{Combination of activated carbon and nylon 6,6 membrane}

The coconut pulp waste activated carbon and nylon 6,6 membrane were combined in order to maximize the TCS removal in water. All the optimum parameters conditions were obtained from the batch adsorption and membrane experiments. The combination test was done using flat sheet membrane test and a stand stirrer. A piece of fabric was installed at the inlet pipe in order to prevent the activated carbon from entrance to the membrane machine. The nylon 6,6 membrane was put in the permeation cell. After the compaction test, $4000 \mathrm{~mL}$ of the TCS solution with initial concentration at $5 \mathrm{mg} / \mathrm{L}$ was poured into the feed tank together with coconut pulp activated carbon. A stand stirrer was setup beside the feed tank with its stirrer pointed in the tank. Then, the TCS solution was stirred with activated carbon for 20 minutes. After that, the inlet valve was opened and TCS solution was filtered with nylon 6,6 membrane. The concentration of TCS permeated from the membrane was collected and analysed.

\subsection{Characterizations of nylon 6,6 membrane}

In this research, the surface structure and morphology of the nylon 6,6 membrane were analysed using Field Emission Scanning Electron Microscopy (FESEM) (FESEM, JEOL 6335fSEM, Japan) test. The test was done for the membrane before and after treatments of TCS solution. As recommended by Jasni et al. [43], before conducting the FESEM test, the samples were coated using a gold sputter of a Bio Rad Polaron Division SEM coating system machine at $10^{-1} \mathrm{Mbar}$ in order to reduce charging. Then, they were inserted in FESEM instrument to analyse their surface structures and morphologies. The magnifications scales were used from $5000 x$ to $10000 x$.

In addition, the functional groups existed on the membrane were analyzed using Fourier Transform Infrared Spectroscopy (FTIR) (Perkin-Elmer spectrum ONE). The FTIR test was recorded in the spectral range of 4000 to $400 \mathrm{~cm}^{-1}$ at resolution 4 $\mathrm{cm}^{-1}$. For the nylon 6,6 membrane, the FTIR analysis was conducted using the Attenuated Total Reflectance (ATR) technique. ATR mode was used because the membrane was 
already in solid form and not in powder form. The ATR technique allows the solid or liquid samples to be examined directly without any preparation in advance.

\section{Results and Discussion \\ 3.1 Characteristics of the nylon 6,6 membrane \\ 3.1.1 Surface morphologies}

The FESEM test was done to analyze the surface morphologies of the nylon 6,6 membrane. Figures 1 (a) and (b) show the FESEM images of this membrane before and after the TCS adsorption, respectively. As can be seen in Figure 1 (a), the morphology of nylon 6,6 fiber threads appear to be thin, smooth, free from beads, and continuous. These results show that, the optimum electrospinning parameters used during the production of nylon 6,6 membrane can produce a quality nanofiber. Based on Figure 1 (b), on the other hand, can be used to analyse the activated carbon after adsorption of TCS. The image shows that the nylon 6,6 nanofiber threads were filled up by a lot of particles until most of the nanofiber threads were covered. This showed that the nylon 6,6 membrane can adsorb and trap TCS particles in aqueous solutions.
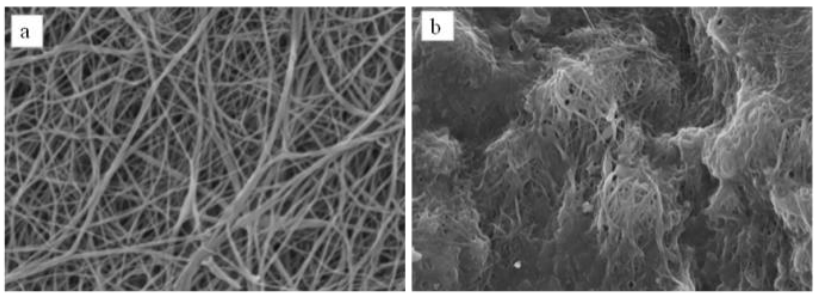

Figure 1: FESEM image of the nylon 6,6 membrane (a) before adsorption (magnification $\mathrm{x} 10000)$ and (b) after TCS adsorption (magnification $\mathrm{x} 5000)$

\subsubsection{Functional groups}

FTIR is one of the important methods to identify and determine the functional groups of adsorbent samples and it influences the occurrence of the adsorption process. Figure 2 shows the FTIR spectra of the nylon 6,6 membrane. According to the obtained results, the nylon 6,6 has a medium band at peak $3298 \mathrm{~cm}^{-1}$ that was attributed to the $\mathrm{N}-\mathrm{H}$ stretch from amino groups [41]. Following this, a $\mathrm{C}-\mathrm{H}$ stretching vibration due to alkanes group was observed with a medium peak at $2934 \mathrm{~cm}^{-1}$. At peaks $1636 \mathrm{~cm}^{-}$ 1 and $1535 \mathrm{~cm}^{-1}$, two strong peaks were detected, and after $1500 \mathrm{~cm}^{-1}$, all the peaks weakened in intensity. The strong peaks formed at peaks range from $1500 \mathrm{~cm}^{-1}$ to $1700 \mathrm{~cm}^{-1}$, due to amide I and II bands [42]. At peak $1636 \mathrm{~cm}^{-1}, \mathrm{C}=\mathrm{O}$ stretching from the carbonyl group can bind with the amino group to form intra molecular hydrogen bonding, causing the $\mathrm{C}=\mathrm{O}$ stretching that normally forms at peak $1760 \mathrm{~cm}^{-1}$ to $1665 \mathrm{~cm}^{-1}$ to be shifted to $1636 \mathrm{~cm}^{-1}$ [43]. Meanwhile, the amide II band at peak $1535 \mathrm{~cm}^{-1}$ appeared due to $\mathrm{C}-\mathrm{N}$ stretching and $\mathrm{N}-\mathrm{H}$ bonding.

$\mathrm{Xu}$ et al. [40] stated that "the hydrogen bonding interactions might play an important role in the sorption processes, because hydrogen bonds could be formed between phenolic hydroxyl group of TCS acting as hydrogen-bonding donors and carbonyl groups of electrospun fibrous membranes". This FTIR test showed that the nylon 6,6 membrane has a carbonyl group and it can produce hydrogen bonding with the hydroxyl group of TCS molecules [43]. Therefore, it can be proven that the chemisorption process happened during the TCS removal using nylon 6,6 membrane.

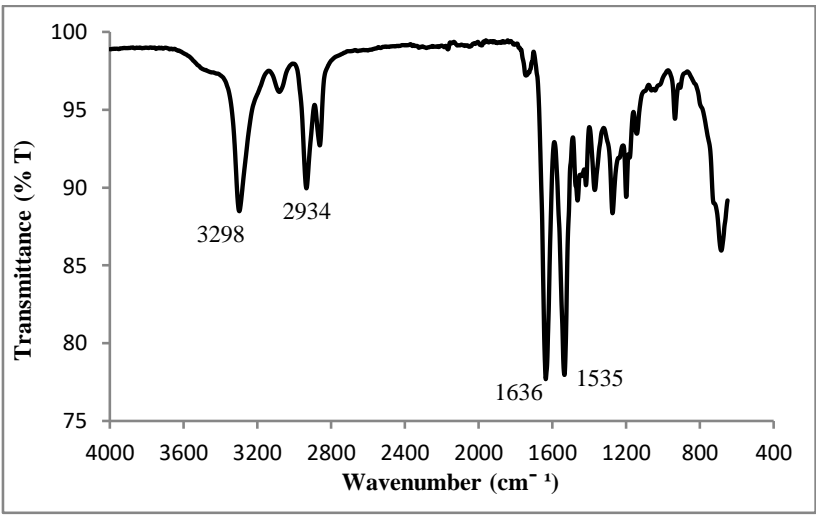

Figure 2: The FTIR spectra of the nylon 6,6 membrane

\subsection{Adsorption studies}

\subsubsection{Contact time}

The contact time was measured to determine the maximum time taken for adsorbate removal and adsorption capacity of the adsorbent until it reaches the equilibrium condition. The effect of contact time was examined through applying $0.1 \mathrm{~g}$ nylon 6,6 membrane to treating $50 \mathrm{ml}$ of $5 \mathrm{mg} / \mathrm{L}$ TCS solution.

In Figure 3, it shows the effect of contact time on TCS removal by the nylon 6,6 membrane. The graph shows that the TCS removal and adsorption capacity increased with an increase of contact time. The TCS removal increased from $40.2 \%$ to $86.3 \%$ by the $4^{\text {th }}$ hour before reaching its equilibrium conditions. Then, the TCS removal started to slightly decrease during the $5^{\text {th }}$ and the $6^{\text {th }}$ hours from $85.3 \%$ to $83.3 \%$. Meanwhile, the adsorption capacity also increased from $1.01 \mathrm{mg} / \mathrm{g}$ to $2.16 \mathrm{mg} / \mathrm{g}$ for 10 minutes during 4 hours of contact time before it decreased from $2.13 \mathrm{mg} / \mathrm{g}$ to $2.08 \mathrm{mg} / \mathrm{g}$ during the $5^{\text {th }}$ to $6^{\text {th }}$ hours of contact time. Therefore, the optimum time taken for TCS removal using nylon 6,6 membrane to reach equilibrium was achieved with 4 hours of contact time.

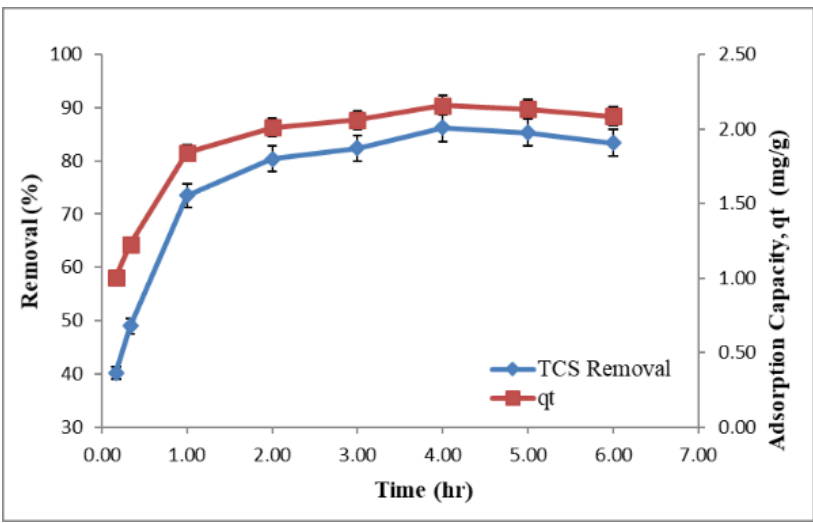

Figure 3: The effect of contact time on the TCS removal using nylon 6,6 membrane

According to the results, the higher and rapid adsorption rates at the initial period were due to the number of vacant sites available at the initial stage on the external surface of nanofibrous adsorbents [49]. On the other hand, the slow adsorption rate from 2 hours to 4 hours of contact time was due to the availability of 
decreased membrane pores and the fact that TCS had to move into deeper sites $[26,49]$. The decrease in removal percentage after equilibrium might also be due to some adsorbate particles which started being released from the adsorbent surface into the solution [30]. The same pattern for adsorption capacity was also achieved in [50] for chitosan/PVA nanofibers to remove nickel and cobalt where it reached equilibrium at $120 \mathrm{~min}$. Razzaz et al. [49] also reported the same trends for adsorption capacity of chitosan/ $/ \mathrm{TiO}_{2}$ nanofibrous for $\mathrm{Pb}$ (II) and $\mathrm{Cu}(\mathrm{II})$ ions removal, reaching equilibrium at $30 \mathrm{~min}$ of contact time.

\subsubsection{Adsorbent dosage}

Adsorbent dosage is a parameter that affects the availability of the adsorption sites. The effect of adsorbent dosage was examined by varying the amount of nylon 6,6 membrane from $0.01 \mathrm{~g}$ to 0.20 g. The experiments were conducted at room temperature to treat $50 \mathrm{ml}$ of $5 \mathrm{mg} / \mathrm{L} \mathrm{TCS}$ solution, at $150 \mathrm{rpm}$. Figure 4 shows the effect of adsorbent dosage on TCS removal using the nylon 6,6 membrane. As depicted by the graph, the removal of TCS increased from $56.9 \%$ to $86.3 \%$ with an increase of membrane mass from $0.01 \mathrm{~g}$ to $0.10 \mathrm{~g}$. However, when the mass of the nylon 6,6 was added in the range of $0.15 \mathrm{~g}$ to $0.20 \mathrm{~g}$, the TCS removal also decreased from $82.4 \%$ to $70.6 \%$. On the other hand, the adsorption capacity of nylon 6,6 membrane was found to decrease by increasing the membrane mass. The adsorption capacity decreased from $14.22 \mathrm{mg} / \mathrm{g}$ to $0.88 \mathrm{mg} / \mathrm{g}$ when the membrane was increased from $0.01 \mathrm{~g}$ to $0.20 \mathrm{~g}$. Thus, the optimum membrane dosage to remove $5 \mathrm{mg} / \mathrm{L}$ TCS solution was achieved with $0.10 \mathrm{~g}$ of the adsorbent.

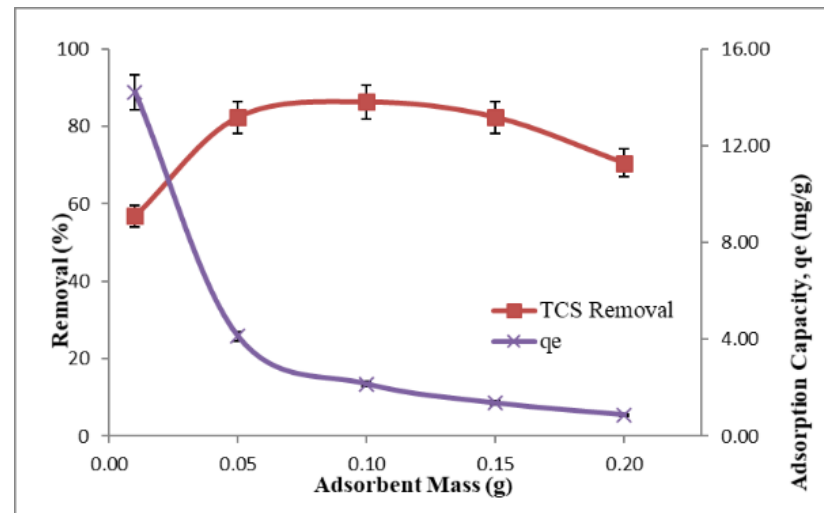

Figure 4: The effect of adsorbent dosage on the TCS removal using nylon 6,6 membrane

The increase in removal percentage from $0.01 \mathrm{~g}$ to $0.10 \mathrm{~g}$ was due to the high surface area and the availability of binding sites for adsorption [51]. As for the decrease in the removal after the optimum dosage was given, it was attributed to the overlapping of adsorption sites due to crowded membranes that would reduce the active sites for adsorption [15]. Moreover, the decrease of adsorption capacity with an increase in the adsorbent dosage was due to the fact that the adsorbent sites available were not fully utilized at a higher adsorbent dosage. When the adsorbents increased, there were more sites available in number which finally reduced the amount of TCS adsorbed for each unit weight of membranes [52]. Additionally, at a high adsorbent dosage, the interfacial tension between two phases increased, which reduced the driving force for the mass transfer, hence reducing the adsorption capacity [53]. A similar trend for effect of membrane dosage was also reported by Li et al. [15] in their study into methylene blue dye removal using calcium algitate membrane. The study achieved the optimum dye removal of $96.0 \%$ using 20 mg of membrane.

\subsubsection{Agitation}

Agitation was performed to ensure the maximum contact of fiber surface with the TCS in the solution [48]. The effect of agitation was investigated by varying the agitation speed of the shaker from $50 \mathrm{rpm}$ to $250 \mathrm{rpm}$. Figure 5 shows the effect of agitation speed on TCS removal using the nylon 6,6 membrane. According to the graph, the optimum TCS removal and absorption capacity of $86.3 \%$ and $2.16 \mathrm{mg} / \mathrm{g}$, respectively, were achieved at $150 \mathrm{rpm}$. A slower speed will reduce mobility and transfer force between TCS and the adsorbent, while a higher speed will lead to weakening of the bonding strength between the TCS and the membrane surface area. It results in low removal percentage and adsorption capacity using activated carbon. Therefore, the best agitation speed for TCS adsorption using the nylon 6,6 membrane was achieved at $150 \mathrm{rpm}$, and it was used for all the other parameters during this study.

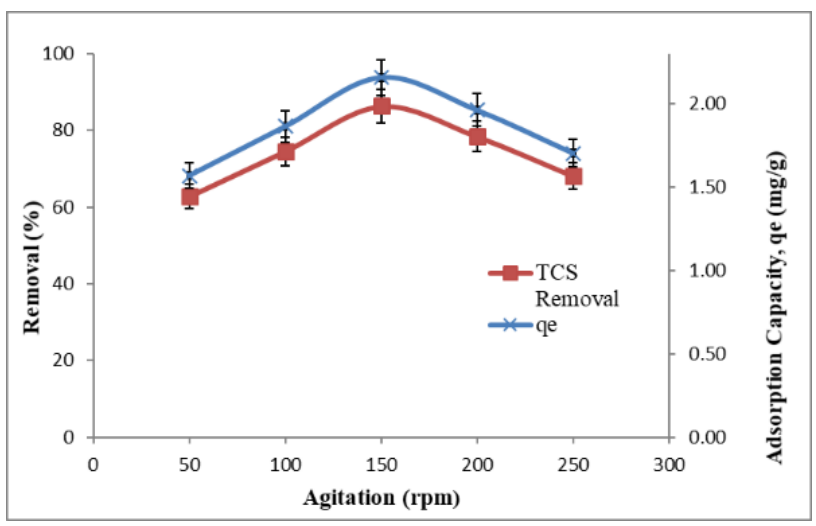

Figure 5: The effect of agitation speed on the TCS removal using nylon 6,6 membrane

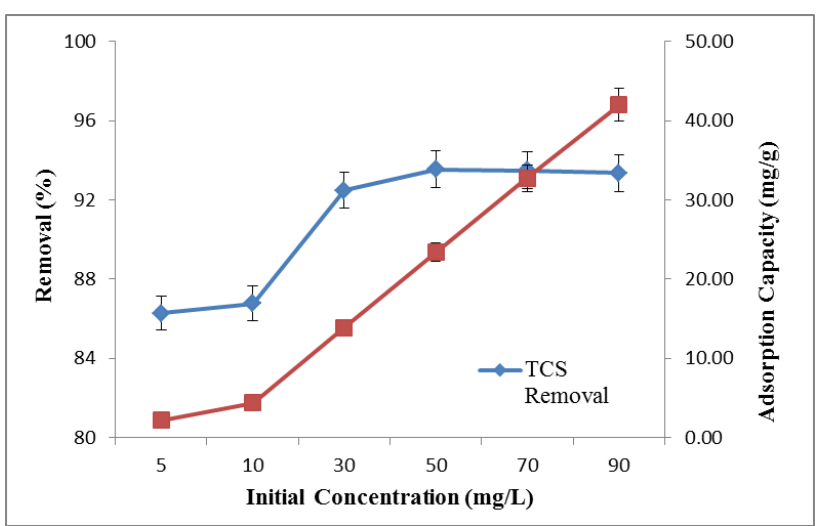

Figure 6: The effect of initial TCS concentration on the TCS removal by using nylon 6,6 membrane

\subsubsection{Initial TCS concentration}

The effects of initial TCS concentrations were tested from 5 $\mathrm{mg} / \mathrm{L}$ to $90 \mathrm{mg} / \mathrm{L}$, while the other parameters were kept constant. Figure 6 shows the effect of initial TCS concentration on its 
removal using nylon 6,6 membrane. From the graph plotted, when the initial concentration of TCS was increased from $5 \mathrm{mg} / \mathrm{L}$ to 50 $\mathrm{mg} / \mathrm{L}$, the TCS removal also increased from $86.3 \%$ to $93.5 \%$. This was due to the many active sites available for the adsorption process at low concentrations [54]. However, when the TCS concentration was increased to $70 \mathrm{mg} / \mathrm{L}$ and $90 \mathrm{mg} / \mathrm{L}$, the removal percentage almost remained constant with a slight decrease to $93.5 \%$ and $93.4 \%$, respectively. According to Feng et al. [55], this could be due to the decrease and the saturation of active sites on the adsorbent surfaces. While the membrane adsorption capacity increased with an increase in the TCS initial concentration. The nylon 6,6 membrane adsorption capacity increased from 2.16 $\mathrm{mg} / \mathrm{g}$ to $42.01 \mathrm{mg} / \mathrm{g}$ in $5 \mathrm{mg} / \mathrm{L}$ to $90 \mathrm{mg} / \mathrm{L}$ TCS concentrations. Increase of the concentration will increase the electrostatic interactions between the adsorbate and adsorbent, hence improving the adsorption capacity of the adsorbent [56].

Literature consists of a number of studies reporting similar trends on the effect of the initial concentration using various nanofibers. Li et al. [15] reported that the adsorption capacity of calcium alginate membrane increased from $520 \mathrm{mg} / \mathrm{g}$ to 1680 $\mathrm{mg} / \mathrm{g}$ when methylene blue initial concentration was increased from $30 \mathrm{mg} / \mathrm{L}$ to $170 \mathrm{mg} / \mathrm{L}$.

\subsubsection{The $\mathrm{pH}$ effect}

The effect of $\mathrm{pH}$ value was tested through fixing it at 3.0-9.0. The $\mathrm{pH}$ values selected were in range of TCS $\mathrm{pk}_{\mathrm{a}}$ value and isoelectric point of the nylon 6,6 membrane. Figure 7 shows the effect of $\mathrm{pH}$ on the TCS removal using the nylon 6,6 membrane.

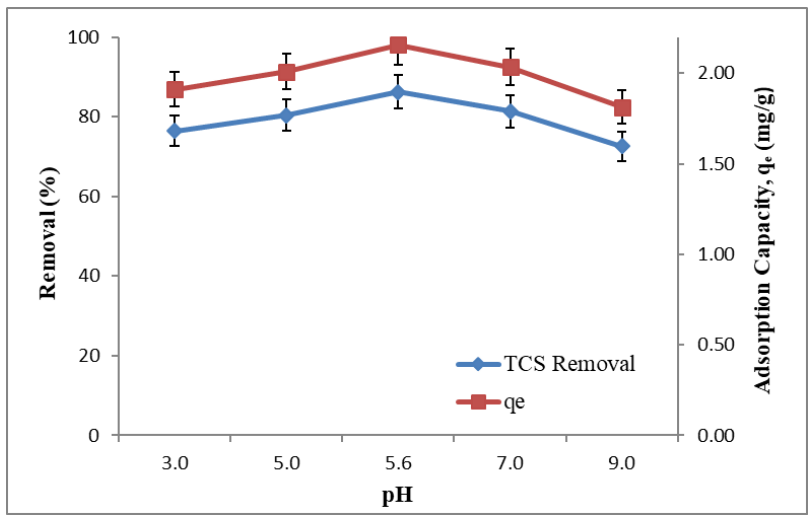

Figure 7: The effect of $\mathrm{pH}$ on the TCS removal using nylon 6,6 membrane

As shown by the graph, the highest removal percentage and adsorption capacity of $86.3 \%$ and $2.16 \mathrm{mg} / \mathrm{g}$, respectively, were achieved at $\mathrm{pH}$ 5.6. The other $\mathrm{pH}$ values resulted in lower TCS removal percentages and adsorption capacities. At a $\mathrm{pH}$ lower than TCS $\mathrm{pk}_{\mathrm{a}}=7.90$, the TCS molecules are available in a protonated form [40]. Based on Jasni et al. [43], the isoelectric point of the nylon 6,6 membrane is at $\mathrm{pH} 5$, where the nylon 6,6 membrane is in positive charge at $\mathrm{pH} 5$ and below, but it turns to negative charge with $\mathrm{pH}$ values higher than 5 . Therefore, the TCS removal and adsorption capacity were low at $\mathrm{pH} 5$ and below due to the electrostatic repulsions between the positive charge of TCS and the positive charge of the nylon 6,6 membrane. On the contrary, for $\mathrm{pH}$ higher than 5 , the nylon 6,6 membrane was turned to the negative charge nanofiber. As a result, it increases both TCS adsorption and adsorption capacity due to attraction forces between the positively charge TCS and the negatively charge membrane. At $\mathrm{pH}$ values higher than 7.90, TCS particles will be deprotonated and become negatively charged. Thus, the electrostatic repulsion between the deprotonated TCS and nanofibers caused a reduction for both TCS removal and adsorption capacity [40]. Xu et al. [40] also reported a similar trend for the adsorption of TCS using electrospun fibrous membranes and achieved the best TCS removal at $\mathrm{pH} 6$ compared to those fixed at $\mathrm{pH} 4,8$, and 10 .

\subsubsection{Temperature}

The surrounding temperature influences the bonding strength between TCS particles and the surface of the membrane. The temperature was varied from $25{ }^{\circ} \mathrm{C}$ to $60{ }^{\circ} \mathrm{C}$ to treat $50 \mathrm{~mL}$ of the $5 \mathrm{mg} / \mathrm{L}$ TCS solution. The experiments were conducted in an incubator shaker. Figure 8 shows the effect of temperature on the TCS removal using the nylon 6,6 membrane. The results show that the TCS removal and adsorption capacity decreased with an increase in temperature. The TCS removal and adsorption capacities both decreased from $86.3 \%$ to $55.9 \%$ and from 2.16 $\mathrm{mg} / \mathrm{g}$ to $1.40 \mathrm{mg} / \mathrm{g}$, respectively, when the temperature was increased from $25^{\circ} \mathrm{C}$ to $60{ }^{\circ} \mathrm{C}$. The melting point of TCS is $57^{\circ} \mathrm{C}$; therefore, TCS solubility in water increases when the temperature increases, hence causing the adsorption process to recede [57]. Furthermore, increasing the temperature weakens the electrostatic interactions between the adsorption surface and adsorbate particles and this will reduce the adsorption capacity and TCS removal [15]. The adsorption of TCS using the nylon 6,6 membrane was an exothermic process since its removal rate and adsorption capacity lowered with the increase of temperature [53].

Aluigi et al. [53] also reported a similar trend for the removal of methylene blue using keratin nanofibrous membrane where the adsorption capacity and the methylene blue removal both decreased from $175 \mathrm{mg} / \mathrm{g}$ to $128 \mathrm{mg} / \mathrm{g}$ and from $68 \%$ to $51 \%$, respectively, when the temperature was increased from $20{ }^{\circ} \mathrm{C}$ to $50{ }^{\circ} \mathrm{C}$.

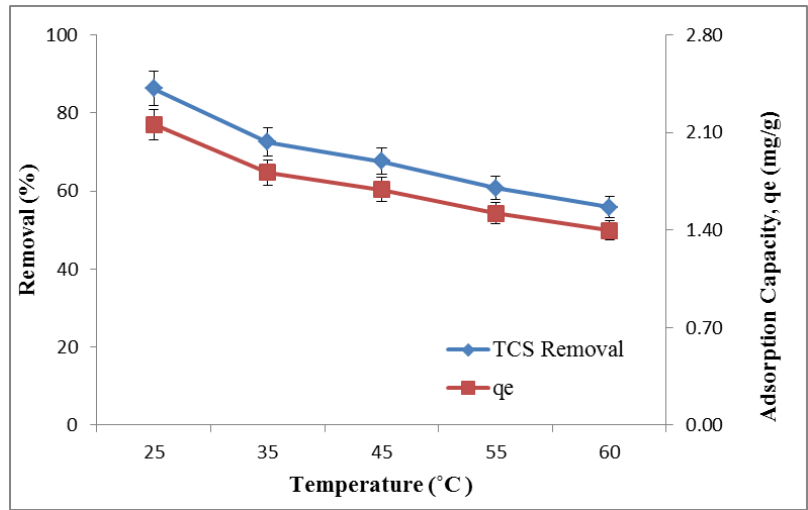

Figure 8: The effect of temperature on the TCS removal using nylon 6,6 membrane

\subsection{Filtration studies \\ 3.3.1 Compaction}

For the filtration method, the pre-compaction test was necessary before the compound filtration process can be done. This procedure was done in order to reduce the interference of compaction with other factors such as fouling, and the test was 
conducted until a steady flux was achieved [58]. The precompaction test was done in order to maximize the water contact in all membrane pores before the filtration test can be done. The time taken to achieve a steady flux can vary based on the types and material of membrane. Hussain and Al-Saleh [58] also stated that the steady flux for ultrafiltration membranes can be reached within minutes, but it will take more time for reverse osmosis membranes. For the compaction test, a volume of $4000 \mathrm{~mL}$ distilled water was used and poured into the feed tank. The test was conducted for 90 minutes while the pressure was set to 1.5 bar.

The water flux achieved during the pre-compaction test using the nylon 6,6 membrane is shown in Figure 9. Based on the results, the water flux decreased from $2028 \mathrm{~L} / \mathrm{m}^{2} \mathrm{~h}$ to $1570 \mathrm{~L} / \mathrm{m}^{2} \mathrm{~h}$ and reached a steady flux in 75 minutes. The compaction process caused the membrane structure porosity to be reduced and a flux reduction occurred [58]. After a steady flux was achieved, the compaction test was stopped and the pressure was reduced to 1.0 bar before continuing further experiments.

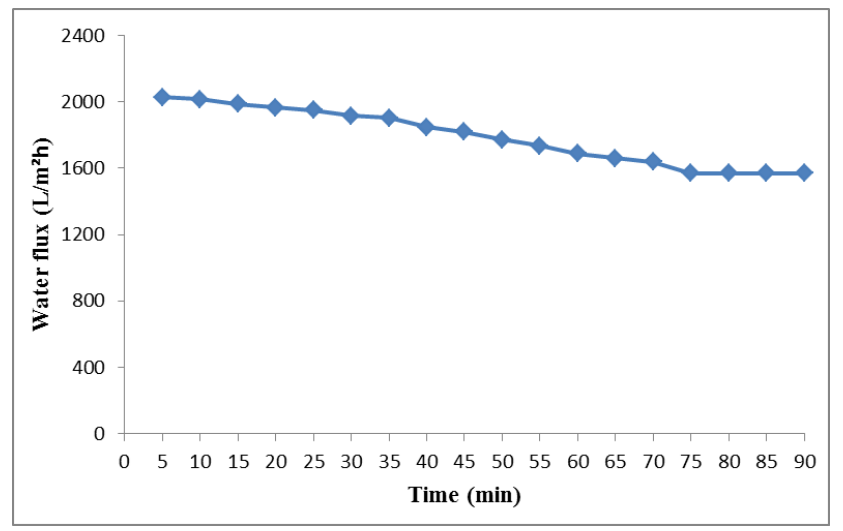

Figure 9: The water flux during pre-compaction test

\subsubsection{Water flux and TCS solution flux analysis}

After the compaction process, the pressure was decreased to 1.0 bar. Subsequently, the flux analysis using distilled water was conducted for 30 minutes at pressure 1.0 bar. Figure 10 shows the distilled water flux, TCS solution flux, and TCS removal within 30 minutes. As can be observed in the figure, the distilled water flux is higher than the TCS solution flux. The water flux was recorded with $1655 \mathrm{~L} / \mathrm{m}^{2} \mathrm{~h}$ during the first 5 minutes before it decreased to $1491 \mathrm{~L} / \mathrm{m}^{2} \mathrm{~h}$ at 30 minutes. As for the TCS solution, the flux also decreased from $1209 \mathrm{~L} / \mathrm{m}^{2} \mathrm{~h}$ to $1062 \mathrm{~L} / \mathrm{m}^{2} \mathrm{~h}$, from 5 to 30 minutes. The reduction of flux when using TCS solution might be due to the presence of TCS particles trapped into the membrane pores, causing their porosity to be reduced for water permeation.

The removal of TCS by filtration method decreased with the increase in time. The TCS removal decreased from $90.2 \%$ to $17.7 \%$ from 5 minutes to 30 minutes. The same results were also reported by Muhamad et al. [47] in their experiment for the removal of BPA using $\mathrm{PES}-\mathrm{SiO}_{2}$ membrane, where the BPA removal decreased from $81 \%$ to $52 \%$ from 10 minutes to 170 minutes during the filtration test. This occurred due to the reduction of adsorption sites available for TCS after its saturation [47]. According to the obtained results, the TCS achieved its maximum removal within 5 minutes of the filtration process.

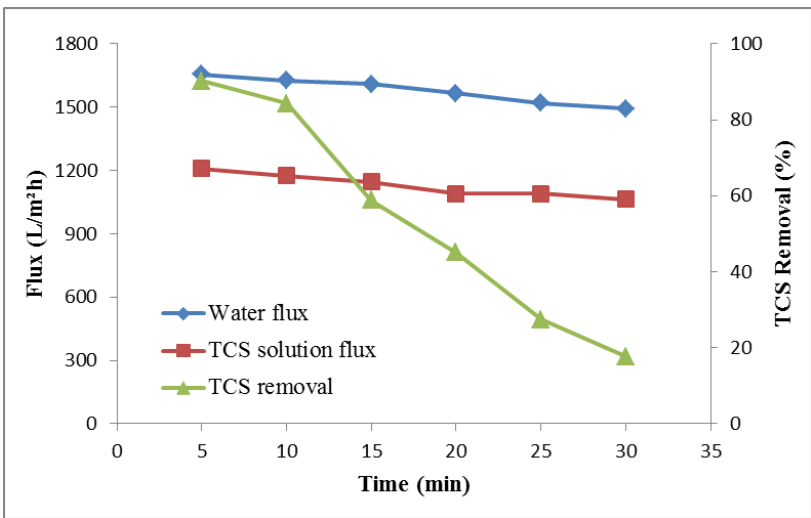

Figure 10: The results of distilled water flux, TCS solution flux, and percentage TCS removal obtained using nylon 6,6 membrane through filtration process

\subsection{The effect of combined activated carbon and membrane on TCS removal}

The combination method was done in order to find the best setting for TCS removal from aqueous solutions. The experiments on the combination method using coconut pulp waste activated carbon and nylon 6,6 membrane were conducted using a flat sheet membrane test machine. The optimal parameters values obtained from previous experiments were used in this process where $4 \mathrm{~L}$ of $5 \mathrm{mg} / \mathrm{L}$ TCS solution was poured into the feed tank with $8.0 \mathrm{~g}$ coconut pulp waste activated carbon and was stirred with a stand stirrer. After 20 minutes of the adsorption process, the TCS solution was filtered using the nylon 6,6 membrane by unfastening the inlet valve from the feed tank. The TCS solution $\mathrm{pH}$ at 5.6, room temperature, and inlet pressure 1.0 bar were set up for this test. Figure 11 shows the TCS removal after combining both the adsorption and filtration methods.

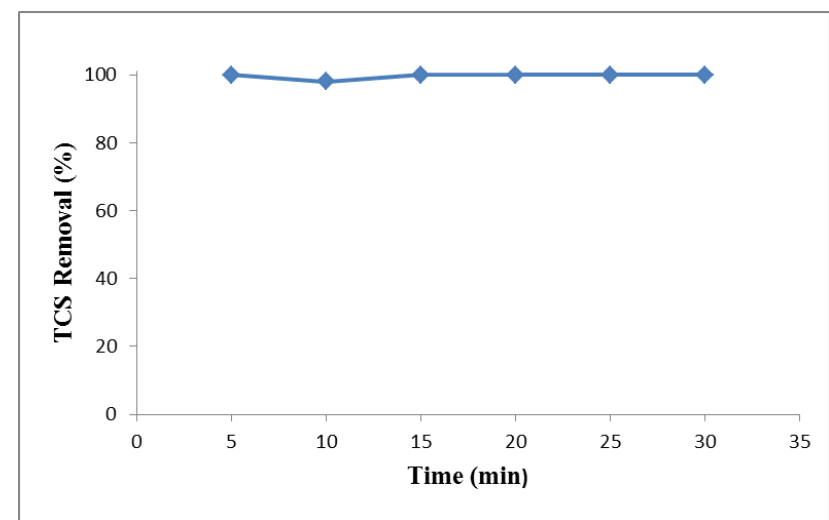

Figure 11: The TCS removal through combining the adsorption method using coconut pulp waste activated carbon and filtration method using nylon 6,6 membrane

According to the obtained results, TCS was removed $100 \%$ in 5 minutes of the filtration process where it already reached its equilibrium. During the adsorption process, most of the TCS particles in the solution were already removed. As such, the nylon 6,6 membrane only filtered the leftover of TCS particles that escaped during the adsorption process. According to Skouteris et al. [59] and Wang et al. [60], the activated carbon can be used as 
a pre-treatment for membrane by removing the majority of dissolved organic matters and inorganic particles in the water, thereby reducing the membrane fouling. Therefore, it shows that this combination method can increase the TCS removal in aqueous solutions within a shorter time.

Similar results were reported by Wang et al. [60], using the combination of coconut shell activated carbon and polyamide $\mathrm{NF}$ membrane to remove dimethyl phthalate, di-(2-ethylhexyl) phthalate and dioctyl phthalate where more than $99 \%$ of removal rate was achieved for all the three chemicals.

\section{Conclusion}

Based on this study, $90.2 \%$ of the TCS removal was achieved using the nylon 6,6 membrane through filtration method within 5 minutes. Then, after combining both coconut pulp waste activated carbon and nylon 6,6 membrane, the TCS removal was increased up to $100 \%$ within less than 5 minutes. Therefore, this combination method can help to increase the TCS removal from the water and reduce the fouling probabilities. Based on the FESEM images, the results showed that the nylon 6,6 membrane had thin, smooth, beads-free, and continuous fibers. While the results of the FTIR test showed that the nylon 6,6 membrane had carbonyl group and it was able to produce hydrogen bonding with hydroxyl group of TCS molecules. Thus, it proved that the chemisorption process happened during the TCS removal using the nylon 6,6 membrane. As a conclusion, combining activated carbon and nylon 6,6 membrane is one of the promising methods that can help to increase the TCS removal from the aqueous solutions.

\section{Aknowledgment}

The authors would like to acknowledge the Ministry of High Education of Malaysia for providing LRGS Grant on Water Security entitled Protection of Drinking Water: Source Abstraction and Treatment (203/PKT/6720006) and Universiti Teknologi Malaysia (R.J130000.7809.4L810, Q.J130000.2522.19H06 and Q.J130000.2422.04G06) as financial support of this project.

\section{Ethical issue}

Authors are aware of, and comply with, best practice in publication ethics specifically with regard to authorship (avoidance of guest authorship), dual submission, manipulation of figures, competing interests and compliance with policies on research ethics. Authors adhere to publication requirements that submitted work is original and has not been published elsewhere in any language.

\section{Competing interests}

The authors declare that there is no conflict of interest that would prejudice the impartiality of this scientific work.

\section{Authors' contribution}

All authors of this study have a complete contribution for data collection, data analyses and manuscript writing

\section{References}

1 Teitelbaum SL, Li Q, Lambertini L, Belpoggi F, Manservisi F, Falcioni L, Bua L, Silva MJ, Ye X, Calafat AM, Chen J. Paired serum and urine concentrations of biomarkers of diethyl phthalate, methyl paraben, and triclosan in rats. Environmental health perspectives. 2015 Jun 5;124(1):39-45.

2 Montaseri $\mathrm{H}$, Forbes $\mathrm{PB}$. A review of monitoring methods for triclosan and its occurrence in aquatic environments. TrAC Trends in Analytical Chemistry. 2016 Dec 1;85:221-231.

3 Zhu W, Zhang H, Tong C, Xie C, Fan G, Zhao S, Yu X, Tian Y, Zhang J. Environmental exposure to triclosan and semen quality. International journal of environmental research and public health 2016 Feb;13(2):224.

4 Dhillon GS, Kaur S, Pulicharla R, Brar SK, Cledón M, Verma M, Surampalli RY. Triclosan: current status, occurrence, environmental risks and bioaccumulation potential. International journal of environmental research and public health, 2015 May 22;12(5):56575684.

5 Shanmugam G, Ramasamy K, Selvaraj KK, Sampath S, Ramaswamy $\mathrm{BR}$. Triclosan in fresh water fish gibelion catla from the Kaveri River, India, and its consumption risk assessment. Environmental Forensics. 2014 Jul 3;15(3):207-212.

6 Eriksson KM, Johansson CH, Fihlman V, Grehn A, Sanli K, Andersson MX, Blanck H, Arrhenius Å, Sircar T, Backhaus T. Longterm effects of the antibacterial agent triclosan on marine periphyton communities. Environmental toxicology and chemistry. 2015 Sep;34(9):2067-2077.

7 Martins D, Monteiro MS, Soares AM, Quintaneiro C. Effects of 4$\mathrm{MBC}$ and triclosan in embryos of the frog Pelophylax perezi. Chemosphere. 2017 Jul 1;178:325-332.

8 Chen J, Meng T, Li Y, Gao K, Qin Z. Effects of triclosan on gonadal differentiation and development in the frog Pelophylax nigromaculatus. Journal of Environmental Sciences. 2018 Feb $1 ; 64: 157-165$.

9 Wang S, Poon K, Cai Z. Removal and metabolism of triclosan by three different microalgal species in aquatic environment. Journal of hazardous materials. 2018 Jan 15;342:643-650.

10 Nag SK, Das Sarkar S, Manna SK. Triclosan-an antibacterial compound in water, sediment and fish of River Gomti, India International journal of environmental health research. 2018 Sep 3;28(5):461-470.

11 Zhang G, Sun M, Liu Y, Liu H, Qu J, Li J. Ionic liquid assisted electrospun cellulose acetate fibers for aqueous removal of triclosan. Langmuir. 2015 Jan 26;31(5):1820-1827.

12 Lee DG, Cho KC, Chu KH. 945201. Removal of triclosan in nitrifying activated sludge: Effects of ammonia amendment and bioaugmentation. Chemosphere. 2015;125:9-15.

13 Xin L, Sun Y, Feng J, Wang J, He D. Degradation of triclosan in aqueous solution by dielectric barrier discharge plasma combined with activated carbon fibers. Chemosphere. 2016 Feb 1;144:855-863.

14 Dou R, Zhang J, Chen Y, Feng S. High efficiency removal of triclosan by structure-directing agent modified mesoporous MIL-53 (Al). Environmental Science and Pollution Research. 2017 Mar 1;24(9):8778-8789.

15 Li J, Zhang Y, Peng J, Wu X, Gao S, Mao L. The effect of dissolved organic matter on soybean peroxidase-mediated removal of triclosan in water. Chemosphere. 2017 Apr 1;172:399-407.

16 Orhon KB, Orhon AK, Dilek FB, Yetis U. Triclosan removal from surface water by ozonation-Kinetics and by-products formation. Journal of environmental management. 2017 Dec 15;204:327-336.

17 Wang F, Liu F, Chen W, Xu R, Wang W. Effects of triclosan (TCS) on hormonal balance and genes of hypothalamus-pituitary-gonad axis of juvenile male Yellow River carp (Cyprinus carpio). Chemosphere. 2017 Feb 1;193:695-701.

18 Wang Y, Li P, Liu Y, Chen B, Li J, Wang X. Determination of triclocarban, triclosan and methyl-triclosan in environmental water by silicon dioxide/polystyrene composite microspheres solid-phase extraction combined with HPLC-ESI-MS. Journal of Geoscience and Environment Protection, 2013 Jan 1;1(02):13-17.

19 Liu Y, Zhu X, Qian F, Zhang S, Chen J. Magnetic activated carbon prepared from rice straw-derived hydrochar for triclosan removal RSC Advances. 2014;4(109):63620-63626. 
20 Behera SK, Oh SY, Park HS. Sorption of triclosan onto activated carbon, kaolinite and montmorillonite: effects of $\mathrm{pH}$, ionic strength, and humic acid. Journal of hazardous materials. 2010 Mar 19;179:684-691.

21 Weiner B, Sühnholz S, Kopinke FD. Hydrothermal Conversion of Triclosan- The Role of Activated Carbon as Sorbent and Reactant. Environmental science \& technology. 2017 Jan 9;51(3):1649-1653.

22 Sharipova AA, Aidarova SB, Bekturganova NE, Tleuova A, Schenderlein M, Lygina O, Lyubchik S, Miller R. Triclosan as model system for the adsorption on recycled adsorbent materials. Colloids and Surfaces A: Physicochemical and Engineering Aspects. 2016 Sep 20;505:193-196.

23 Zhu X, Liu Y, Luo G, Qian F, Zhang S, Chen J. Facile fabrication of magnetic carbon composites from hydrochar via simultaneous activation and magnetization for triclosan adsorption. Environmental science \& technology. 2014 Apr 29;48(10):5840-5848.

24 Tong Y, Mayer BK, McNamara PJ. Triclosan adsorption using wastewater biosolids-derived biochar. Environmental Science: Water Research \& Technology. 2016;2(4):761-768.

25 Pezoti O, Cazetta AL, Bedin KC, Souza LS, Martins AC, Silva TL, Júnior OO, Visentainer JV, Almeida VC. NaOH-activated carbon of high surface area produced from guava seeds as a high-efficiency adsorbent for amoxicillin removal: Kinetic, isotherm and thermodynamic studies. Chemical Engineering Journal. 2016 Mar $15 ; 288: 778-788$

26 Wirasnita R, Hadibarata T, Yusoff AR, Yusop Z. Removal of bisphenol A from aqueous solution by activated carbon derived from oil palm empty fruit bunch. Water, Air, \& Soil Pollution. 2014 Oct $1 ; 225(10): 2148$

27 Ghanbarnejad P, Goli A, Bayat B, Barzkar H, Amirreza T, Bagheri M, Alaee S. Evaluation of formaldehyde adsorption by human hair and sheep wool in industrial wastewater with high concentration. Journal of Environmental Treatment Techniques. 2014 Mar 9;2(1):12-17.

28 AssefaAragaw T. Proximate analysis of cane bagasse and synthesizing activated carbon: emphasis on material balance. Journal of Environmental Treatment Techniques. 2016 Oct 6;4(4):102-110.

29 Rahmat NA, Ali AA, Hussain N, Muhamad MS, Kristanti RA, Hadibarata T. Removal of Remazol Brilliant Blue $\mathrm{R}$ from aqueous solution by adsorption using pineapple leaf powder and lime peel powder. Water, Air, \& Soil Pollution. 2016 Apr 1;227(4):105.

30 Lazim ZM, Hadibarata T, Puteh MH, Yusop Z, Wirasnita R, Nor NM. Utilization of durian peel as potential adsorbent for bisphenol a removal in aquoeus solution. Jurnal Teknologi. 2015 May 9;74(11): 109-115.

31 Njoku VO, Islam MA, Asif M, Hameed BH. Preparation of mesoporous activated carbon from coconut frond for the adsorption of carbofuran insecticide. Journal of analytical and applied pyrolysis. 2014 Nov 1;110:172-180.

32 Kamari A, Yusoff SN, Abdullah F, Putra WP. Biosorptive removal of $\mathrm{Cu}$ (II), $\mathrm{Ni}$ (II) and $\mathrm{Pb}$ (II) ions from aqueous solutions using coconut dregs residue: Adsorption and characterisation studies. Journal of Environmental Chemical Engineering. 2014 Dec 1;2(4):1912-1919.

33 Dabwan AH, Yuki N, Asri NA, Katsumata H, Suzuki T, Kaneco S. Removal of methylene blue, rhodamine $\mathrm{B}$ and ammonium ion from aqueous solution by adsorption onto sintering porous materials prepared from coconut husk waste. Open Journal of Inorganic Nonmetallic Materials. 2015 Feb 2;5(02):21.

34 Hettiarachchi E, Perera R, Chandani Perera AD, Kottegoda N Activated coconut coir for removal of sodium and magnesium ions from saline water. Desalination and water treatment. 2016 Oct 7;57(47):22341-22352.

35 Jawad AH, Rashid RA, Mahmuod RM, Ishak MA, Kasim NN, Ismail $\mathrm{K}$. Adsorption of methylene blue onto coconut (Cocos nucifera) leaf: optimization, isotherm and kinetic studies. Desalination and Water Treatment. 2016 Apr 20;57(19):8839-8853.

36 Kaman SP, Tan IA, Lim LL. Palm oil mill effluent treatment using coconut shell-based activated carbon: Adsorption equilibrium and isotherm. InMATEC Web of Conferences 2017 (Vol. 87, p. 03009). EDP Sciences.

37 Salehi F. Current and future applications for nanofiltration technology in the food processing. Food and Bioproducts Processing. 2014 Apr 1;92(2):161-177.

38 Padaki M, Murali RS, Abdullah MS, Misdan N, Moslehyani A, Kassim MA, Hilal N, Ismail AF. Membrane technology enhancement in oil-water separation. A review. Desalination. 2015 Feb 2;357:197207.

39 Zheng X, Zhang Z, Yu D, Chen X, Cheng R, Min S, Wang J, Xiao Q, Wang J. Overview of membrane technology applications for industrial wastewater treatment in China to increase water supply. Resources, Conservation and Recycling. 2015 Dec 1;105:1-10.

40 Xu, J., Niu, J., Zhang, X., Liu, J., Cao, G., \& Kong, X. (2015). Sorption of triclosan on electrospun fibrous membranes: Effects of $\mathrm{pH}$ and dissolved organic matter. Emerging Contaminants, 1(1), 2532.

41 Jasni MJ, Sathishkumar P, Sornambikai S, Yusoff AR, Ameen F Buang NA, Kadir MR, Yusop Z. Fabrication, characterization and application of laccase-nylon $6,6 / \mathrm{Fe} 3+$ composite nanofibrous membrane for 3, 3'-dimethoxybenzidine detoxification. Bioprocess and biosystems engineering. 2017 Feb 1;40(2):191-200.

42 An T, Pant B, Kim SY, Park M, Park SJ, Kim HY. Mechanical and optical properties of electrospun nylon-6, 6 nanofiber reinforced cyclic butylene terephthalate composites. Journal of industrial and engineering chemistry. 2017 Nov 25;55:35-39.

43 Jasni MJ, Arulkumar M, Sathishkumar P, Yusoff AR, Buang NA, Gu FL. Electrospun nylon 6, 6 membrane as a reusable nano-adsorben for bisphenol A removal: Adsorption performance and mechanism. Journal of colloid and interface science. 2017 Dec 15;508:591-602.

44 Bilad MR, Azizo AS, Wirzal MD, Jia LJ, Putra ZA, Nordin NA Mavukkandy MO, Jasni MJ, Yusoff AR. Tackling membrane fouling in microalgae filtration using nylon 6, 6 nanofiber membrane. Journal of environmental management. 2018 Oct 1;223:23-28.

45 Mohd Khori NK, Hadibarata T, Elshikh MS, Al-Ghamdi AA, Yusop $\mathrm{Z}$. Triclosan removal by adsorption using activated carbon derived from waste biomass: Isotherms and kinetic studies. Journal of the Chinese Chemical Society. 2018 Aug;65(8):951-959.

46 Cheng M, Zeng G, Huang D, Yang C, Lai C, Zhang C, Liu Y. Advantages and challenges of Tween 80 surfactant-enhanced technologies for the remediation of soils contaminated with hydrophobic organic compounds. Chemical Engineering Journal, 2017 Jan 7;314:98-113.

47 Muhamad MS, Salim MR, Lau WJ, Hadibarata T, Yusop Z. Removal of bisphenol A by adsorption mechanism using PES-SiO2 composite membranes. Environmental technology. 2016 Aug 2;37(15):19591969.

48 Habiba U, Afifi AM, Salleh A, Ang BC. Chitosan/(polyvinyl alcohol)/zeolite electrospun composite nanofibrous membrane for adsorption of $\mathrm{Cr} 6+, \mathrm{Fe} 3+$ and $\mathrm{Ni} 2+$. Journal of hazardous materials 2017 Jan 15;322:182-194.

49 Razzaz A, Ghorban S, Hosayni L, Irani M, Aliabadi M. Chitosan nanofibers functionalized by $\mathrm{TiO} 2$ nanoparticles for the removal of heavy metal ions. Journal of the Taiwan Institute of Chemical Engineers. 2016 Jan 1;58:333-343

50 Esmaeili A, Beni AA. A novel fixed-bed reactor design incorporating an electrospun PVA/chitosan nanofiber membrane. Journal of hazardous materials. 2014 Sep 15;280:788-796.

51 Muhamad MH, Abdullah SR, Hasan HA, Rahim RA, Bakar SN, Ismail N, Halmi MI. Adsorption Isotherm and Kinetic Studies of Pentachlorophenol Removal from Aqueous Solution onto Coconut Shell-based Granular Activated Carbon. Journal of Environmental Science and Technology. 2018 Jan 1;11(2):68-78. 
52 Maneechakr P, Karnjanakom S. Adsorption behaviour of Fe (II) and $\mathrm{Cr}$ (VI) on activated carbon: Surface chemistry, isotherm, kinetic and thermodynamic studies. The Journal of Chemical Thermodynamics. 2017 Mar 1;106:104-112.

53 Aluigi A, Rombaldoni F, Tonetti C, Jannoke L. Study of Methylene Blue adsorption on keratin nanofibrous membranes. Journal of hazardous materials. 2014 Mar 15;268:156-165.

54 Abu-Saied MA, Wycisk R, Abbassy MM, El-Naim GA, ElDemerdash F, Youssef ME, Bassuony H, Pintauro PN. Sulfated chitosan/PVA absorbent membrane for removal of copper and nickel ions from aqueous solutions-fabrication and sorption studies. Carbohydrate polymers. 2017 Jun 1;165:149-158.

55 Feng Q, Wu D, Zhao Y, Wei A, Wei Q, Fong H. Electrospun AOPAN/RC blend nanofiber membrane for efficient removal of heavy metal ions from water. Journal of hazardous materials. 2018 Feb 15;344:819-828.

56 Alipour D, Keshtkar AR, Moosavian MA. Adsorption of thorium (IV) from simulated radioactive solutions using a novel electrospun PVA/TiO2/ZnO nanofiber adsorbent functionalized with mercapto groups: Study in single and multi-component systems. Applied Surface Science. 2016 Mar 15;366:19-29.

57 Xu R, Si Y, Wu X, Li F, Zhang B. Triclosan removal by laccase immobilized on mesoporous nanofibers: strong adsorption and efficient degradation. Chemical Engineering Journal. 2014 Nov 1;255:63-70.

58 Hussain YA, Al-Saleh MH. A viscoelastic-based model for TFC membranes flux reduction during compaction. Desalination. $2014 \mathrm{Jul}$ 1;344:362-370.

59 Skouteris G, Saroj D, Melidis P, Hai FI, Ouki S. The effect of activated carbon addition on membrane bioreactor processes for wastewater treatment and reclamation-a critical review. Bioresource technology. 2015 Jun 1;185:399-410.

60 Wang L, Wan Q, Wu J, Guo M, Mao S, Lin J. Removal of Phthalate Esters by Combination of Activated Carbon with Nanofiltration. InSustainable Development of Water Resources and Hydraulic Engineering in China 2019 (pp. 269-273). Springer, Cham. 